\title{
Atmospheric Water Generation (AWG): Performance Model and Economic Analysis
}

\author{
Faraz Moghimi ${ }^{1}$, Hamed Ghoddusi ${ }^{2}$, Bahram Asiabanpour ${ }^{1}$, and Mahdi \\ Behroozikhah ${ }^{3}$ \\ 1 Texas State University, \\ 2 Stevens Institude of Technology \\ 3 University of California, San Diego
}

\begin{abstract}
United Nation's 2018 Water Development Report estimated that more than 2 Billion people all around the world lack access to clean drinking water. In addition, many of our freshwater sources are declining. Therefore, exploring new methods of collecting clean drinking water is vital. Use of Atmospheric Water Generators (AWG) is one of these methods with the potential to contribute towards the salvation of our water problems. However, AWGs performance is quite volatile in different environmental conditions and its economic feasibility is questionable. In this paper, an indicator model is developed to predict AWG's performance in different conditions. This model is then used to examine the performance of AWG in Austin, Texas during a 4 year period. An economic analysis is carried out on the performance of the AWG system for a 4 year period from a single users' perspective that exhibited an NPV value of $\$ 5964$. This analysis showed that AWGs may indeed be financially feasible when utilized in Austin's environment.
\end{abstract}

Keywords: Atmospheric Water Generators · AWG. Water Crisis · Economic Analysis · Modelling · Prediction · Feasibility Analysis · Environmental Factors

\section{Introduction}

United Nation's 2018 Water Development Report [1] estimated that more than 2 Billion people all around the world lack access to clean drinking water. Moreover, the freshwater sources available to us are being drained faster than they are being refilled $[2,3]$. Thus, many of the freshwater sources are declining around the world. To add on, the general demand for water has been constantly increasing during the last few decades due to the population growth and creation of new industries. Taking all of this into account, exploring new methods of harvesting clean water is vital. In addition, examining the water industry from an economic

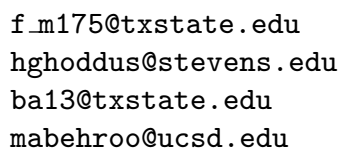


point of view, it can be seen that the quality of the drinking water matters more and more to the consumer as the general quality of life increases. The thriving bottled water industry is a perfect example that producing safe, well tasting water can be quite profitable.

One of the alternative methods of clean water harvesting is the use of Atmospheric Water Generators (AWG). AWGs produce clean water from the humidity in the air by condensing the vaporized water in the atmosphere [4]. AWGs may prove to be part of the solution towards fixing our water problems while making for a profitable industry along the way. However, AWG's performance is quite volatile; heavily relying on environmental factors like humidity and temperature [5]. To add on, the AWG industry is relatively young and not many data exist on accurate estimations of AWGs' volatile performance in different conditions. So, the economic feasibility of AWGs is still questionable. Most of the scholarly work in the area focuses on improving the technology aspect of the AWG. Therefore, there is a lot of room to explore the AWGs from a business point of view and analyze the potential AWGs available today carry in the market. In this paper, the focus would be to develop a model capable of estimating the performance of AWGs in different weather conditions, use this model to examine the performance of AWGs in the city of Austin, and carry out an economic analysis of implementing AWGs in Austin, Texas from a single users' perspective.

\section{Methodology}

\subsection{Atmospheric Water Generators}

The moisture in the earth's atmosphere may not be the most abundant source of water. However, it more or less exists on every side of the planet; sometimes it is in great quantity and in regions with an extreme need for new sources of water. Atmospheric Water Generators (AWG) extract moisture in the air and condense it to liquid water [4]. AWG systems typically consist of an energy source, compressors, pumps, fans, storage, a variety of pipes, and a filtration system, figure 1 . To put it in simple words, the vaporized water would get in the system through the fans, go through condensation and then be purified with flirtations and UV lights. To add on, this system generally produces distilled water. So, a lot of the AWGs that being utilized to produce drinking water use components to add sufficient minerals to make the produced water taste good and better suited for long term drinking. AWGs are manufactured in a variety of scales for different purposes like resident's drinking use, agricultural use, and industrial use. In this study, the focus would be on the application AWGs to produce clean drinking water.

\subsection{Production model}

AWG's performance heavily relies on a variety of weather conditions. To be more specific, humidity and temperature play a big role in how much water the system 


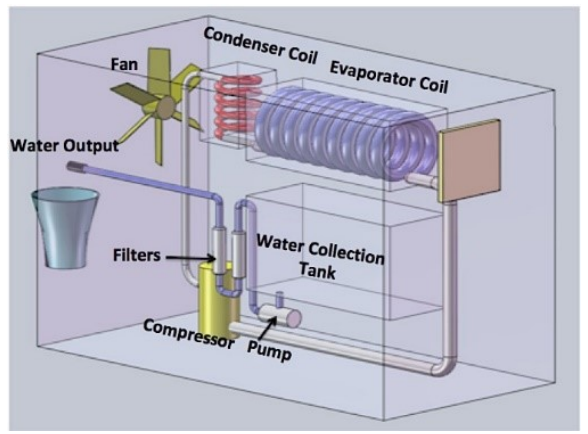

Fig. 1. atmospheric water generators break down

is able to produce. Table 1 is published by an AWG manufacturer as a measure of predicting the daily performance for a small size AWG in different weather conditions (Aquaboy2 [6]). Other manufacturers have published similar tables for their products as well. However, The Atmospheric Water Generators are a relatively new industry. Thus, most products in the market lack the detailed data description indicating the machines performance in different conditions. They often lack in presenting any sort of indication altogether. In this study, the analysis would be based on the AWG machine Aquaboy2, the experiments carried out on it, and the manufacturers reports published on that specific product. As it can be seen at table 1, the provided estimates have a lot of gaps in between those specified conditions. Therefore, to be capable of predicting AWGs performance at any given condition, linear regression is utilized to generate a general model. This model would be capable of predicting the daily production of the AWG system at any humidity and temperature. After developing the model, a 4-year weather data from 2014 to 2018 for the city of Austin is collected from the National Center For Environmental Information[7]. This data exhibits the daily average of temperature and humidity. The generated model would then be tested using this data to examine the performance of the AWG system during the 4 year period in the city of Austin, Texas.

Table 1. Daily water production estimation in liters published by the manufacturer. Temperature is measured in Fahrenheit and humidity is measured in percentage.

\begin{tabular}{cccccc} 
Humidity/Temp & 55 & 68 & 77 & 86 & 95 \\
\hline 30 & \multicolumn{3}{l}{3.79} & 4.73 & 5.68 \\
40 & 3.79 & 4.73 & 6.81 & 8.9 & \\
50 & 3.79 & 4.73 & 6.81 & 7.95 & 14.38 \\
60 & 3.97 & 5.87 & 7.95 & 11.73 & 19.87 \\
70 & 5.87 & 7.19 & 11.73 & 15.52 & 20.82 \\
80 & 5.87 & 7.76 & 14.57 & 18.36 & \\
90 & 7.57 & 17.03 & 20.82 &
\end{tabular}




\subsection{Energy consumption}

A 10-day data collection, recording the performance and energy consumption of the same AWG model was done by Asiabanpour [5]. This data collection was during the warm season and took place in San Marcos, Texas. In this study, another 10-day data collection during the cold season was added. Having in mind that AWGs are heavily reliant on weather conditions, another data collection in a different season would help better perceive the system. The collected data shown in table 2 is used to calculate an average daily energy consumption level for AWGs.

Table 2. 20 day experiment data recording the water production in liters and Energy consumption in Kwh.

\begin{tabular}{c|c|c} 
Day & Water production & Energy Consumption \\
\hline 1 & 4.385 & 6.26 \\
\hline 2 & 5.88 & 7.38 \\
\hline 3 & 11.34 & 12.67 \\
\hline 4 & 11.25 & 10.54 \\
\hline 5 & 11.85 & 11.63 \\
\hline 6 & 11.75 & 10.97 \\
\hline 7 & 11.625 & 10.91 \\
\hline 8 & 11.6 & 10.75 \\
\hline 9 & 11.075 & 10.8 \\
\hline 10 & 13.8 & 10.68 \\
\hline 11 & 1.75 & 7.32 \\
\hline 12 & 2 & 7.43 \\
\hline 13 & 2.5 & 7.92 \\
\hline 14 & 6.71 & 8.6 \\
\hline 15 & 4.35 & 7.99 \\
\hline 16 & 3.7 & 8.3 \\
\hline 17 & 7.1 & 9.06 \\
\hline 18 & 2.55 & 8.08 \\
\hline 19 & 1.45 & 8 \\
\hline 20 & 0.625 & 4.35 \\
\hline & &
\end{tabular}

\subsection{Economic analysis}

The daily performance model would provide the daily production forecast for the 4 year period. This would allow the created added value on each day to be estimated. In this section, the economic analysis is done for AWGs in Austin as an alternative to bottled drinking water. Thus, the created value on each day in terms of US dollars is calculated by assuming that the produced water is worth as much as a large package of bottled water in Austin. So, according to eBay [8], a 60 pack of 16.9 oz bottled water would cost $\$ 24.99$ at the consumers door. 
In other words, the value of bottled water is $\$ 0.83$ per liter at the costumers door. In addition, electrical energy is priced at $\$ 0.12$ per KWH [9] on average in the city of Austin. Moreover, the primary cost of purchasing the AWG system is $\$ 1664$ and it would cost approximately yearly $\$ 200$ to maintain the filtration of the system. Also, the salvage value of the machine is considered 0 at the end of year 4. Taking all of this into account, negative and positive cash flows are created for the entirety of the 4 year period. The Net Present Value (NPV) is calculated for this project with a $5 \%$ annual interest rate. This economic analysis would determine how much money would a person who has chosen to use AWG instead of bottled water would save in US dollars during the 4 year use of AWGs in Austin.

$$
N P V=\sum_{n=0}^{n} \frac{C t}{(1+r)^{n}}
$$

where

$C t$ : cash inflow during the period $\mathrm{t}$

Co : initial investment costs

$r$ : the discount rate

$t$ : the number of time periods

\section{$3 \quad$ Results}

\subsection{Production estimation}

The production model was developed using linear regression in python and is shown in equation 2 . The model showed to be a good representation of the input data as it provides a $92 \% R^{2}$ value. This equation is used to predict the 4-year performance in Austin. Fig 2 exhibits the daily water production of the AWG in Austin over the time period.

$$
\begin{aligned}
\text { Production }(\text { Liters })= & -0.0003 \times \text { Temperature }-0.01815 \times \text { Humidity } \\
& +0.0053 \times \text { Temperature } \times \text { Humidity }-3.7513
\end{aligned}
$$

Where the parameters are measured in:

Production : Liters

Temperature : Fahrenheit

Humidity : Percentage

\subsection{Economic analysis}

The average daily energy consumption according to the collected data is 8.982 Kwh. Having that value the NPV for this 4 year project is calculated and it can be seen in table 3 . 


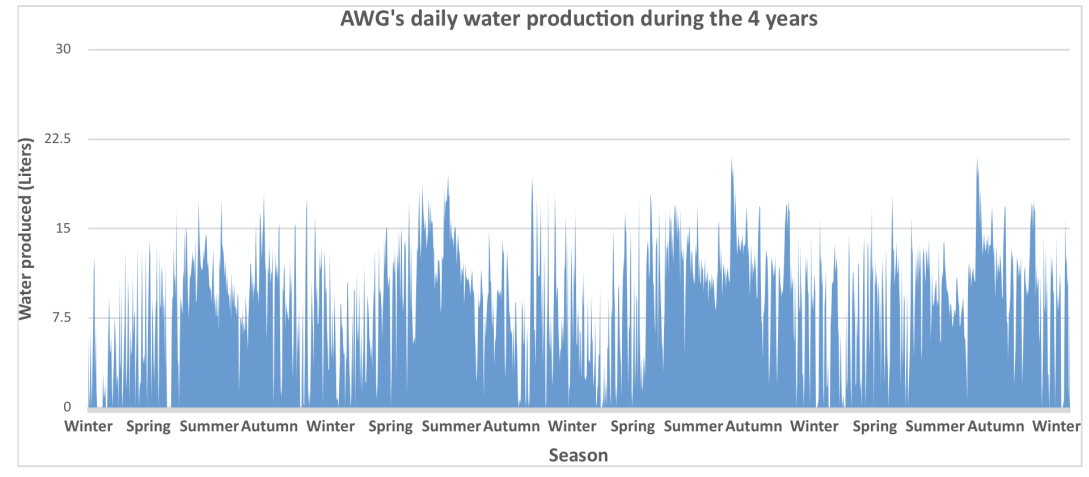

Fig. 2. Estimated water production for the whole span of the 4 year period.

Table 3. Economic analysis results for the 4 year project.

\begin{tabular}{l|l} 
Interest rate & $5 \%$ \\
\hline Initial purchase & $\$ 1,664$ \\
\hline Yearly maintenance & $\$ 200$ \\
\hline Daily electricity cost & $\$ 1.08$ \\
\hline Value of produced water per liter & $\$ 0.83$ \\
\hline Salvage value & 0 \\
\hline NPV & $\$ 5,964.82$
\end{tabular}

\section{Discussion of results and conclusion}

The performance of AWG during the four years shows an interesting pattern. As it can be seen on fig 2, the AWG system performs a lot better in warm seasons than it does in colder seasons. The summers show the highest water production and the winters are the least efficient. This is of importance since it can push the idea that Atmospheric Water Generators are seasonal products. It can also, lead the AWG industry towards exploring markets with warmer environments. Even with the volatile performance, AWG shows a lot of promise in the performance predictions and economic analysis. The $\$ 5964.82 \mathrm{NPV}$ shows that AWGs in Austin can be profitable and cost-efficient. This illustrates that if a person drinks AWG water instead of bottled water, he or she would save $\$ 5964.82$ in the present value of money over 4 years. This study hopes to contribute towards examining the potential that AWG industry can have in the future to be a part of the solution for our water problems.

We should bear in mind the limitations of this paper as well. The developed performance model provides a tool to predict the AWG's production level. However, given this model was developed with limited data and based on a variety of assumptions, it can only provide a long term macro perspective on AWG performance. Hence, it should not be considered as the most accurate source to predict the AWG's production on a specific day. Moreover, this study assumes 
that electricity consumption and energy rates are constant factors throughout the four-year span. This approach serves well to provide a general look on AWG's financial promise over a long period of time. However, predicting the exact financial promise especially in a shorter time scale is a much more complex task. Also, this paper considers AWG only as an alternative to bottled drinking water. In addition, it can be seen that AWG's potential heavily relies on environmental factors and regional economic parameters. Thus, the results of this study for the Austin area should not be generalized to other regions with different environmental and economic factors.

For future work, the production model can be improved to generate more accurate predictions of any potential environment for AWG's use. In addition, developing an accurate energy consumption model could help make our look at the system more comprehensive. In addition, given the access to larger data sets, a variety of Machine Learning (ML) techniques such as Support Vector Machines (SVM) and Neural Networks can be utilized to achieve a more accurate performance model. Analyzing more influencing economic parameters will help better understand the financial aspect of the AWGs. Moreover, considering the heavy reliance AWGs have on regional weather and economic factors, examining the performance of AWGs in different regions can be quite exciting as well.

\section{Acknowledgement}

This work was completed with funding from the US Department of Agriculture (Grant \# 2016-38422-25540). The authors would like to thank the USDA and Texas State University for providing funding and access to both infrastructure and laboratories. The sponsors are not responsible for the content and accuracy of this article. The authors declare that there is no conflict of interest regarding the publication of this paper.

\section{References}

1. Gilbert F. Houngbo. The United Nations world water development report 2018: nature-based solutions for water. 2018.

2. Alexandra S. Richey, Brian F. Thomas, Min-Hui Lo, John T. Reager, James S. Famiglietti, Katalyn Voss, Sean Swenson, and Matthew Rodell. Quantifying renewable groundwater stress with grace. Water Resources Research, 51(7):5217-5238, 2015.

3. The 11 cities most likely to run out of drinking water - like cape town; bbc news. https://bbc.com/news/world-42982959. Published: 11 Feb. 2018.

4. Zaid Almusaied and Bahram Asiabanpour. Atmospheric water generation: Technologies and influential factors. IIE Annual Conference.Proceedings, pages 14481453, 2017. Copyright - Copyright Institute of Industrial and Systems Engineers (IISE) 2017; Last updated - 2018-02-01.

5. Bahram Asiabanpour, Natalie Ownby, Mark Summers, and Faraz Moghimi. Atmospheric water generation and energy consumption: An empirical analysis. In 2019 IEEE Texas Power and Energy Conference (TPEC), pages 1-6. IEEE, 2019. 
6. Aquaboy pro ii. https://www.atmosphericwatersolutions.com/aquaboy-pro-ii. Accessed: 4 Apr, 2019.

7. Noaa. https://www.ncdc.noaa.gov. Accessed: 15 Apr, 2019.

8. ebay online market. https://tinyurl.com/y69j2t3d. Accessed: 15 Apr, 2019.

9. Texas electricity rates. https://www.texaselectricityratings.com/electricityrates/texas/austin. Accessed: 15 Dec, 2018. 